\title{
Prevalence of clarithromycin resistance in Helicobacter pylori in Santiago, Chile, estimated by real-time PCR directly from gastric mucosa
}

\author{
Patricio Gonzalez-Hormazabal ${ }^{1 *}$ (ID, Maher Musleh ${ }^{2,3}$, Susana Escandar ${ }^{2}$, Hector Valladares $^{2,3}$, Enrique Lanzarini ${ }^{2,3}$, \\ V. Gonzalo Castro ${ }^{1}$, Lilian Jara ${ }^{1}$ and Zoltan Berger ${ }^{2}$
}

\begin{abstract}
Background: Current available treatments for Helicobacter pylori eradication are chosen according to local clarithromycin and metronidazole resistance prevalence. The aim of this study was to estimate, by means of molecular methods, both clarithromycin and metronidazole resistance in gastric mucosa from patients infected with H.pylori.

Methods: A total of 191 DNA samples were analyzed. DNA was purified from gastric mucosa obtained from patients who underwent an upper gastrointestinal endoscopy at an university hospital from Santiago, Chile, between 2011 and 2014. H.pylori was detected by real-time PCR. A 5'exonuclease assay was developed to detect A2142G and A2143G mutations among H.pylori-positive samples. $r d x A$ gene was sequenced in samples harboring A2142G and A2143G mutations in order to detect mutations that potentially confer dual clarithromycin and metronidazole resistance.

Results: Ninety-three (93) out of 191 DNA samples obtained from gastric mucosa were H.pylori-positive (48.7\%). Clarithromycin-resistance was detected in 29 samples (31.2\% [95\%Cl 22.0-41.6\%]). The sequencing of $r d x A$ gene revealed that two samples harbored truncating mutations in $r d x A$, one sample had an in-frame deletion, and 11 had amino acid changes that likely cause metronidazole resistance.

Conclusions: We estimated a prevalence of clarithomycin-resistance of 31.8\% in Santiago, Chile. Three of them harbor inactivating mutations in $r d x A$ and 11 had missense mutations likely conferring metronidazole resistance. Our results require further confirmation. Nevertheless, they are significant as an initial approximation in reevaluating the guidelines for H.pylori eradication currently used in Chile.
\end{abstract}

Keywords: Helicobacter pylori, Clarithromycin, Metronidazole, 235 rRNA, rdxA, Mutation

\section{Background}

Helicobacter pylori is a gram-negative bacillus that colonizes the gastric mucosa. The infection is associated with both gastric and extragastric diseases such as peptic ulcer disease, gastric atrophy, gastric adenocarcinoma, gastric MALT (mucosa-associated lymphoid tissue)

\footnotetext{
* Correspondence: patriciogonzalez@uchile.cl

${ }^{1}$ Human Genetics Program, Institute of Biomedical Sciences, School of Medicine, University of Chile, Av. Independencia 1027, 8380453 Santiago, CL, Chile

Full list of author information is available at the end of the article
}

lymphoma, and iron deficiency anemia. The evidence strongly suggests that H.pylori eradication is beneficial in treatment or prevention of those diseases [1]. One treatment for H.pylori eradication is the triple-therapy that comprises clarithromycin, amoxicillin, and proton pump inhibitor (PPI), nevertheless, triple-therapy is not recommended in regions with high clarithomycin resistance rate [1]. Global claritrhomycin-resistance rates in adults are contrasted among various countries, from $1 \%$ in The Netherlands to $37.6 \%$ in Italy [2]. In light of this observation, the last Maastricht V/Florence consensus

(c) The Author(s). 2018 Open Access This article is distributed under the terms of the Creative Commons Attribution 4.0 International License (http://creativecommons.org/licenses/by/4.0/), which permits unrestricted use, distribution, and reproduction in any medium, provided you give appropriate credit to the original author(s) and the source, provide a link to the Creative Commons license, and indicate if changes were made. The Creative Commons Public Domain Dedication waiver (http://creativecommons.org/publicdomain/zero/1.0/) applies to the data made available in this article, unless otherwise stated. 
on management of H.pylori [1] recommends that in high-clarithromycin resistance regions $(>15 \%$ resistance prevalence), quadruple therapy is necessary. If dual clarithromycin and metronidazole resistance is $>15 \%$, bismuth-containing quadruple therapy is the recommended first-line treatment.

Clarithromycin belongs to the class of macrolide antibiotics. The mechanism of action is the inhibition of protein synthesis of bacteria by binding to the $23 \mathrm{~S}$ ribosomal subunit (23S rRNA). Mutations in the peptidyltransferase region encoded in domain $\mathrm{V}$ of $23 \mathrm{~S}$ rRNA are responsible for macrolide resistance [3]. Three mutations in the $23 \mathrm{~S}$ rRNA gene account for nearly all clarithromycin-resistant (ClaR) strains: A2143G, A2142G and A2142C to a small extent [3]. Standard method (antibiogram), after culture or molecular tests, can be used to detect H.pylori and clarithromycin resistance directly from the gastric biopsy [1]. Epidemiological studies evaluating regional clarithromycin resistance have been conducted based on detection of A2142G and A2143G in DNA isolated from gastric biopsies $[4,5]$. Commercial tests detecting both mutations are available [3], performing at a sensitivity rate of $>94 \%$ and a specificity rate of $>98.5 \%$ compared to the culture susceptibility test. Recently, Tamayo et al. [6] found a high concordance between Etest for clarithromycin and 23S rRNA mutations. To date, only Garrido and Toledo [7] have evaluated primary resistance of H.pylori to clarithromycin in clinical isolates from Santiago, Chile. They found primary resistance in 10 out of 50 isolates by agar dilution. Resistant isolates harbor A2142G or A2143G mutations.

Metronidazole is a nitroimidazole synthesized as an inactive antibiotic prodrug. The bactericidal effect of the drug is mainly explained by the cytotoxic effect of molecules resulting from a reduction of metronidazole intracellularly in facultative anaerobic bacteria. Reduction of metronidazole in H.pylori is mediated mainly by a nonessential oxygen-insensitive NADPH nitroreductase encoded by the $r d x A$ gene. NADPH-flavin-oxidoreductase (FrxA) is also involved in the reduction of metronidazole [3]. Various authors found that metronidazole resistance arises from inactivating mutations in $r d x A$ found only in resistant isolates, and missense mutations have also been involved in metronidazole resistance [8]. On the other hand, the role of inactivating mutations in the $f r x A$ gene is controversial since truncating mutations have been found in sensitive isolates, and some studies report that frxA mutations alone may not be enough to confer resistance [8]. Vallejos et al. [9] studied resistance to clarithromycin and metronidazole in 50 isolates obtained from patients in Santiago, Chile. Forty-five and twenty percent respectively were resistant, resulting in $13.2 \%$ of the prevalence of dual clarithromycin and metronidazole resistance.

The aim of the present study was to estimate clarithomycin resistance in 93 clinical isolates from Santiago,
Chile. To do so, we developed a test to detect A2142G and A2143G mutations in 23S gene by 5'nuclease assay. We also aimed to detect mutations in the $r d x A$ gene among $\mathrm{ClaR}$ isolates.

\section{Methods \\ Subjects}

Subjects invited to participate were patients who underwent a physician-requested upper gastrointestinal endoscopy, at the Department of Gastroenterology at the University of Chile Clinical Hospital between July 2011 and July 2014. Participants were asked to donate a sample of gastric mucosa obtained from antrum and corpus. This study was approved by the Ethical Committee of the following institutions: University of Chile School of Medicine (\#023/2011), and University of Chile Clinical Hospital (\#029/2011). The study was performed in accordance with the Declaration of Helsinki. DNA was isolated from gastric mucosa using FavorPrep Tissue DNA Extraction Mini Kit (Favorgen Biotech Corp, Taiwan, China). Samples were identified as H.pylori-positive or H.pylori-negative by detection of the $16 \mathrm{~S}$ rRNA gene by real-time PCR as described by Kobayashi et al. [10].

\section{Analysis of 23S rRNA mutations}

A segment of the 23S rRNA gene from position 1911 to 2200 was amplified by PCR using primers described by Agudo et al. [11], and sequenced by Sanger sequencing (Service provided by Macrogen Inc., Korea). A 5'exonuclease assay was developed to detect A2142G and A2143G mutations. We designed primers and probes for each allele in highly conserved regions from position 1911 to 2200, comparing sequences obtained from 44 randomly selected H.pylori-positive subjects recruited for this study. Both mutations were tested in separate assays. Primers were: F: 5'-GAGCTGTCTCAACCAGAG-3' and R: 5'-GCGCATGATATTCCCATTA-3'. Probes detecting 2142G (5'-CAAGACGGGAAGACCCC-3') and 2143G (5'-CAAGACGGAGAGACCCC-3') alleles were dual-labeled with $5^{\prime} \mathrm{FAM}-3^{\prime} \mathrm{BHQ} 1$, and the probe complementary to the 2142A - 2143A allele (5'-CAAGACGGAAAGACCCCG-3') was dual-labeled with 5'HEX-3'BHQ1. Primers and probes were synthesized at Macrogen Inc. (Korea). The 5 'exonuclease was carried out in a StepOne Real Time PCR system (Applied Biosystems, USA) using 5X HOT FIREPol Probe qPCR Mix Plus (ROX) (Solis BioDyne, Estonia) according to manufacturer's directions.

\section{Detection of mutations in $r d x A$ gene}

The sequence of $r d x A$ was obtained from samples harboring 23S 2142G or 2143G. Primers for PCR amplification of $r d x A$ (F: 5'-CRTTAGGGATTTTATTGTATGC-3' R: 5'-CTCTTRCCCAAWGCGATC-3') were designed with AliView 1.18 for Linux in conserved regions after 
comparing 83 sequences of H.pylori obtained from GenBank. PCR was performed using Q5 Hot Start High Fidelity DNA Polymerase (New England Biolabs, USA) according to manufacturer's directions, using an annealing temperature of $56^{\circ} \mathrm{C}$. Electrophoretograms were obtained by Sanger sequencing (Service provided by Macrogen Inc., Korea).

\section{Results}

A total of 191 subjects were included in this study, 124 were female $(64.9 \%)$ and 67 male (35.1\%). The median age was 46 years (range 19 years to 82 years). None of them was treated for H.pylori eradication.
Ninety-three (93) out of 191 DNA samples obtained from gastric mucosa were H.pylori-positive (48.7\%). Clarithomycin resistance was detected using a 5'exonuclease assay in 29 samples (31.2\% [95\%CI 22.0-41.6\%]). Of them, 9 harbored 2142G (31.0\%) and 20 (69.0\%) harbored 2143G. All ClaR samples were confirmed by Sanger sequencing. Both Sanger sequencing and 5'exonuclease allowed us to detect heteroresistance, i.e., the coexistence of resistant and susceptible bacterial strains in the same patient [12]. Sixteen (16) out of 93 H.pylori subjects were homoresistant to clarithromycin (17.2\%). In addition, we detected heteroresistance in 13 out of 93 patients (14.0\%).

Table 1 Missense changes and truncating mutations in the $r d x A$ gene among 28 clarithromycin-resistant samples

\begin{tabular}{|c|c|c|c|c|c|c|c|c|c|c|c|c|c|c|c|c|c|c|c|c|c|}
\hline & & רo a & $\mathrm{d} \mathrm{po}$ & $i^{a}$ & & & & & & & & & & & & & & & & & \\
\hline Sample & 6 & 16 & 31 & 49 & 53 & 62 & 67 & 73 & 75 & 88 & 90 & 97 & 98 & 118 & 123 & 151 & 162 & 166 & 172 & 175 & 183 \\
\hline $26695^{\mathrm{b}}$ & Q & $R$ & $T$ & $\mathrm{~T}$ & $\mathrm{H}$ & $\mathrm{L}$ & A & N & E & S & R & $\mathrm{H}$ & G & A & v & v & G & P & v & E & A \\
\hline EN02 & $\mathrm{H}$ & . & $E$ & . & . & . & . & . & . & . & K & $\mathrm{T}$ & . & . & . & . & & . & I & $Q^{d}$ & . \\
\hline EN05 & . & . & $E$ & . & . & & . & . & . & . & . & . & . & . & . & . & & A & I & . & . \\
\hline EN07 & $\mathrm{H}$ & . & $E$ & . & . & & $V^{d}$ & . & & . & K & & . & $\mathrm{T}$ & . & . & & & . & . & . \\
\hline EN11 & . & . & . & . & . & & . & . & . & . & K & . & . & . & . & . & & . & I & . & . \\
\hline EN15 & $\mathrm{H}$ & . & . & . & R & V & . & . & & P & . & & $S$ & . & . & L & & . & I & . & . \\
\hline EN16 & $\mathrm{H}$ & . & . & . & R & V & . & . & . & P & . & $\mathrm{T}$ & . & . & . & . & & . & . & . & . \\
\hline EN20 & & $\mathrm{H}$ & . & & & . & & & . & & & . & & $\mathrm{T}$ & & & . & . & I & & \\
\hline EN30 & . & . & & . & . & & . & . & & . & . & $Y$ & . & . & . & . & & $S$ & . & . & V \\
\hline EN33 & $\mathrm{H}$ & & . & & & . & . & & Q & & & . & & & & & . & . & & & \\
\hline EN36 & $\mathrm{H}$ & . & . & . & $x^{d}$ & . & . & . & . & . & . & . & . & . & . & . & & . & . & . & . \\
\hline EN42 & & & . & . & & . & . & . & . & . & . & . & $S$ & . & & . & . & . & I & Q & . \\
\hline EN61 & . & . & $E$ & . & . & & . & . & . & . & K & . & . & . & . & . & & . & I & Q & . \\
\hline EN70 & $\mathrm{H}$ & . & $E$ & . & . & & . & . & . & . & K & & . & . & . & . & & . & I & Q & V \\
\hline EN82 ${ }^{c}$ & . & . & . & . & . & . & . & . & . & . & . & . & . & . & . & . & & . & . & . & ${ }^{\prime}$ \\
\hline EN89 & & & $E$ & . & & . & . & . & . & . & . & $Y$ & . & $\mathrm{T}$ & & . & . & . & & . & . \\
\hline EN97 & $\mathrm{H}$ & . & . & . & . & & . & . & . & . & K & . & $S$ & . & $\mathrm{T}$ & . & & . & I & Q & \\
\hline EN115 & $\mathrm{H}$ & & . & & & . & $V^{d}$ & & . & & & . & & & & & . & . & & & . \\
\hline EN117 & . & . & $E$ & . & . & & . & . & & . & . & & . & . & . & . & & . & I & Q & . \\
\hline EN125 & & & & & & . & & & . & & & . & & $\mathrm{T}$ & & & . & . & I & Q & \\
\hline EN131 & . & . & . & . & . & & . & . & . & . & . & . & . & . & . & . & & . & . & . & . \\
\hline EN137 & & & $E$ & . & & . & . & . & . & & . & $Y$ & . & & $\mathrm{T}$ & . & . & . & & . & . \\
\hline EN148 & . & . & $E$ & . & . & & . & . & . & . & . & . & . & . & . & . & & . & I & Q & V \\
\hline EN155 & $\mathrm{H}$ & & . & . & . & . & . & $x^{d}$ & & . & . & & . & . & . & . & & & . & . & . \\
\hline EN161 & $\mathrm{H}$ & . & . & . & R & V & . & . & . & P & . & . & $S$ & . & . & L & & . & I & . & . \\
\hline EN167 & $\mathrm{H}$ & . & $E$ & . & . & & . & . & . & . & . & Y & . & . & $\mathrm{T}$ & . & $\mathrm{R}^{\mathrm{d}}$ & . & & . & . \\
\hline EN179 & $\mathrm{H}$ & . & $E$ & . & . & & . & . & . & . & . & . & . & $\mathrm{T}$ & . & . & & . & I & Q & V \\
\hline EN187 & & & . & M & & . & . & . & . & . & & . & . & & & & . & . & & . & . \\
\hline EN190 & $\mathrm{H}$ & $\mathrm{H}$ & $E$ & . & . & & . & . & & . & K & & . & $\mathrm{T}$ & . & . & & & . & . & . \\
\hline
\end{tabular}

a(.): same amino acid as for reference strain

${ }^{b}$ Corresponds to amino acid sequence of RdxA from strain 26,695

In-frame deletion of 39 nucleotides which causes the deletion of amino acids 80 to 92

${ }^{d}$ Coexistence of both nucleotide substitutions in the same sample. X: Stop codon 
The $r d x A$ gene was sequenced in $28 \mathrm{ClaR}$ samples. One ClaR sample was not available at the time of analysis. A nonsense substitution (H53stop) was found in one sample; and an insertion of A at nucleotide 186, leading to a frameshift resulting in N73stop, was found in a different sample. Therefore, two samples harbored truncating mutations in $r d x A$. One sample had an in-frame deletion of 39 nucleotides which causes the deletion of amino acids 80 to 92 (ASALMVVCSLKPS). Table 1 shows the amino acid variations in $r d x A$ found in ClaR samples.

\section{Discussion}

A total of 29 out of the 93 H.pylori positive samples resulted resistant to clarithomycin (31.2\%). This estimation is higher than the $20 \%$ of ClaR reported by Garrido and Toledo in Chile [7]. Taken together, ClaR resistance reported for Chile is above the suggested 15\% threshold to abandon triple-therapy, according to the recommendation of Maastricht V/Florence consensus [1].

Among $28 \mathrm{ClaR}$ samples, two of them harbored truncating mutations and one an in-frame deletion in $r d x A$, and therefore are likely resistant to metronidazole. A total of 22 amino acid substitutions was found. Thirteen of them (Q6H, T31E, H53R, L62 V, R90K, H97T, H97Y, G98S, A118T, V123 T, V172I, E175Q, A183V) have been previously observed in metronidazole-resistant (MtzR) as well as in metronidazole-sensitive strains [13-17]. Therefore, those substitutions probably do not confer resistance to metronidazole. Four substitutions (R16H, A67V, S88P and G162R) were found in 8 samples. R16H and S88P have been observed only in MtzR strains [13-15]. In fact, Arg 16 is one of the residues of RdxA that interacts with the cofactor flavin mononucleotide (FMN) [18]. A67V corresponds to the replacement of a small alanine by a bulky valine in the protein core, and is associated with resistance $[8$, 19]. Analysis from the crystallographic data of RdxA reveals that G162 is involved in FMN binding [18]. Hence, missense mutations R16H, A67V, S88P and G162R likely cause MtzR. Nevertheless, phenotypic testing is needed to confirm that those mutations actually cause MtzR.

Five amino acid changes in RdxA (T49 M, E75Q, V151 L, P166A and P166S) have not been described previously in the literature. None of them have been observed as an important amino acid for the RdxA function. We predicted the effect of those substitutions using the crystallographic data of RdxA protein (Protein Data Bank accession number 3QDL) in the I-Mutant Suite server [20], which estimates protein stability changes (expressed as delta delta $G$ values) upon single-point mutations from the protein structure. Delta-delta $\mathrm{G}$ values and the prediction were as follows: T49 $\mathrm{M}=-0.41$ (neutral stability), $\mathrm{E} 75 \mathrm{Q}=-0.78$ (large decrease of stability), $\mathrm{V} 151 \mathrm{~L}=-0.44$ (neutral stability), P166A $=-1.28$ (large decrease in stability), $\mathrm{P} 166 \mathrm{~S}=-1.50$ (large decrease in stability). Thus, we propose that E75Q (1 sample), P166A (1 sample), and P166S (1 sample) could confer MtzR. However, a phenotypic testing shloud be carry out to confirm it.

\section{Conclusions}

We estimated a prevalence of ClaR of 31.2\% in Santiago, Chile, which is above the suggested $15 \%$ threshold to abandon triple-therapy, according to the recommendation of Maastricht V/Florence consensus. Three out of $28 \mathrm{ClaR}$ samples harboring inactivating mutations in $r d x A$ may be clearly MtzR, and 11 of them had missense mutations in $r d x A$ likely confering MtzR. Further phenotypic testing is needed to obtain a clinically significant conclusion from $r d x A$ sequencing results. Nevertheless, the estimated prevalence of ClaR is significant as an approximation in re-evaluating the triple-therapy for H.pylori eradication currently used in Chile.

Abbreviations

ClaR: Clarithromycin-resistant; PPI: Proton pump inhibitor

\section{Acknowledgements}

We would like to acknowledge Paul Zuckerman for his help in proofreading the manuscript.

\section{Funding}

This work was supported by Fondo Nacional de Desarrollo Científico y Tecnológico -Chile- (FONDECYT) [1151015]. The authors declare that the funding body had no participation in the design of the study and collection, analysis, and interpretation of data and in writing the manuscript.

\section{Availability of data and materials}

The data that support the findings of this study are available from the corresponding author upon reasonable request.

\section{Authors' contributions}

PGH conceived, designed the study and drafted the manuscript. PGH, MM and ZB were responsible for analysis and interpretation of data. VGC and LJ performed molecular analysis. MM, SE, HV and EL were involved in acquisition of samples and data. All authors read and approved the final manuscript.

\section{Ethics approval and consent to participate}

This study was approved by the Ethical Committee of the following institutions: University of Chile School of Medicine (\#023/2011), and University of Chile Clinical Hospital (\#029/2011). The study was performed in accordance with the Declaration of Helsinki. All subjects are adults and gave written informed consent.

Competing interests

The authors declare that they have no competing interests.

\section{Publisher's Note}

Springer Nature remains neutral with regard to jurisdictional claims in published maps and institutional affiliations.

\section{Author details}

${ }^{1}$ Human Genetics Program, Institute of Biomedical Sciences, School of Medicine, University of Chile, Av. Independencia 1027, 8380453 Santiago, CL, Chile. ${ }^{2}$ Department of Gastroenterology, University of Chile Clinical Hospital, Santiago, Chile. ${ }^{3}$ Department of Surgery, University of Chile Clinical Hospital, Santiago, Chile. 
Received: 23 May 2017 Accepted: 7 June 2018

Published online: 20 June 2018

\section{References}

1. Malfertheiner P, Megraud F, O'Morain CA, Gisbert JP, Kuipers EJ, Axon AT, et al. Management of Helicobacter pylori infection-the Maastricht V/ Florence consensus report. Gut. 2017;66:6-30.

2. De Francesco V, Giorgio F, Hassan C, Manes G, Vannella L, Panella C, et al. Worldwide H. pylori antibiotic resistance: a systematic review. J Gastrointestin Liver Dis. 2010;19:409-14.

3. Nishizawa T, Suzuki H. Mechanisms of helicobacter pylori antibiotic resistance and molecular testing. Front Mol Biosci. 2014;1:19.

4. Navarro-Jarabo JM, Fernández-Sánchez F, Fernández-Moreno N, HervasMolina AJ, Casado-Caballero F, Puente-Gutierrez JJ, et al. Prevalence of primary resistance of helicobacter pylori to clarithromycin and levofloxacin in southern Spain. Digestion. 2015;92:78-82.

5. Park JY, Dunbar KB, Mitui M, Arnold CA, Lam-Himlin DM, Valasek MA, et al. Helicobacter pylori clarithromycin resistance and treatment failure are common in the USA. Dig Dis Sci. 2016;61:2373-80.

6. Tamayo E, Montes M, Fernández-Reyes M, Lizasoain J, Ibarra B, Mendarte U, et al. Clarithromycin resistance in Helicobacter pylori and its molecular determinants in Northern Spain, 2013-2015. J Glob Antimicrob Resist. 2017:9:43-6.

7. Garrido L, Toledo H. Novel genotypes in helicobacter pylori involving domain $V$ of the 23S rRNA gene. Helicobacter. 2007:12:505-9.

8. Jones KR, Cha J-H, Merrell DS. Who's winning the war? Molecular mechanisms of antibiotic resistance in helicobacter pylori. Curr Drug Ther. 2008;3:190-203.

9. Vallejos C, Garrido L, Cáceres D, Madrid AM, Defilippi C, Defilippi C, et al. Prevalencia de la resistencia a metrodinazol, claritromicina y tetraciclina en Helicobacter pylori aislado de pacientes de la Región Metropolitana. Rev Med Chil. 2007;135:287-93.

10. Kobayashi D, Eishi Y, Ohkusa T, null I, Suzuki T, Minami J, et al. Gastric mucosal density of helicobacter pylori estimated by real-time PCR compared with results of urea breath test and histological grading. J Med Microbiol. 2002;51:305-11.

11. Agudo S, Pérez-Pérez G, Alarcón T, López-Brea M. Rapid detection of clarithromycin resistant helicobacter pylori strains in Spanish patients by polymerase chain reaction-restriction fragment length polymorphism. Rev. Espanola Quimioter. Publicacion of. Soc. Espanola Quimioter. 2011;24:32-6.

12. De Francesco V, Giorgio F, lerardi E, D'Ercole C, Hassan C, Zullo A. Helicobacter pylori clarithromycin resistance assessment: are gastric antral biopsies sufficient? Gastroenterol Insights. 2012;4:2.

13. Solcà NM, Bernasconi MV, Piffaretti JC. Mechanism of metronidazole resistance in helicobacter pylori: comparison of the rdxA gene sequences in 30 strains. Antimicrob Agents Chemother. 2000:44:2207-10.

14. Bereswill S, Krainick C, Stähler F, Herrmann L, Kist M. Analysis of the rdxA gene in high-level metronidazole-resistant clinical isolates confirms a limited use of rdxA mutations as a marker for prediction of metronidazole resistance in helicobacter pylori. FEMS Immunol Med Microbiol. 2003;36:193-8.

15. Matteo MJ, Pérez CV, Domingo MR, Olmos M, Sanchez C, Catalano M. DNA sequence analysis of rdxA and frxA from paired metronidazole-sensitive and -resistant helicobacter pylori isolates obtained from patients with heteroresistance. Int J Antimicrob Agents. 2006;27:152-8.

16. Albert JM, Al-Mekhaizeem K, Neil L, Dhar R, Dhar PM, Al-Ali M, et al. High prevalence and level of resistance to metronidazole, but lack of resistance to other antimicrobials in helicobacter pylori, isolated from a multiracial population in Kuwait. Aliment Pharmacol Ther. 2006;24:1359-66.

17. Kim SY, Joo YM, Lee HS, Chung I-S, Yoo Y-J, Merrell DS, et al. Genetic analysis of helicobacter pylori clinical isolates suggests resistance to metronidazole can occur without the loss of functional rdxA. J Antibiot (Tokyo). 2009;62:43-50.

18. Martínez-Júlvez M, Rojas AL, Olekhnovich I, Espinosa Angarica V, Hoffman PS, Sancho J. Structure of RdxA-an oxygen-insensitive nitroreductase essential for metronidazole activation in helicobacter pylori. FEBS J. 2012;279:4306-17.

19. Secka O, Berg DE, Antonio M, Corrah T, Tapgun M, Walton R, et al. Antimicrobial susceptibility and resistance patterns among helicobacter pylori strains from the Gambia, West Africa. Antimicrob Agents Chemother. 2013;57:1231-7.

20. Capriotti $E$, Calabrese R, Casadio R. Predicting the insurgence of human genetic diseases associated to single point protein mutations with support vector machines and evolutionary information. Bioinformatics. 2006:22:2729-34.

\section{Ready to submit your research? Choose BMC and benefit from:}

- fast, convenient online submission

- thorough peer review by experienced researchers in your field

- rapid publication on acceptance

- support for research data, including large and complex data types

- gold Open Access which fosters wider collaboration and increased citations

- maximum visibility for your research: over $100 \mathrm{M}$ website views per year

At BMC, research is always in progress.

Learn more biomedcentral.com/submissions 